\title{
TRUE PANCREATIC CYST - A CASE REPORT
}

Shivanand Melkundi ${ }^{1}$, Neha Anand ${ }^{2}$

HOW TO CITE THIS ARTICLE:

Shivanand Melkundi, Neha Anand. "True Pancreatic Cyst - A Case Report". Journal of Evolution of Medical and Dental Sciences 2014; Vol. 3, Issue 03, January 20; Page: 657-659, DOI: 10.14260/JEMDS/2014/1881

ABSTRACT: We are presenting a rare case of 45 year old female from Gulbarga came to hospital for regular checkup. Patient was subjected to ultrasound and incidentally a well-defined cystic lesion was noted arising from tail of pancreas. Later patient underwent CECT and it was finally diagnosed as true pancreatic cyst.

KEYWORD: True pancreatic cyst.

INTRODUCTION: True pancreatic cysts often result from anomalous development of pancreatic ducts. They can be unilocular or multilocular. ${ }^{1}$ Individuals of any race, gender or age may be affected. Many patients present without abdominal complaints. ${ }^{2}$ Cyst varies from small size to as large as $15 \mathrm{~cm}$. The number of patients diagnosed with pancreatic cystic lesions has increased during the last decade, when the availability for high quality imaging studies has increased. ${ }^{3}$

CASE SUMMARY: A 45 year old female from Gulbarga came to the hospital for regular checkup. On clinical examination there was no evidence of organomegaly or tenderness. There was no history of pancreatitis, alcohol abuse, stone disease or abdominal trauma. ${ }^{3}$ Liver function test showed normal enzyme levels. Tumor markers were normal. Serum amylase and lipase were normal.

Ultrasound: A well-defined anechoic cystic lesion measuring 9x7cm was noted arising from tail of pancreas. On color Doppler no flow was noted within the lesion or periphery of the lesion. Head and body of pancreas appeared normal. Pancreatic duct appeared normal. No evidence of peri-pancreatic fluid collection, calcification or peripancreatic lymphadenopathy was noted.

Non-contrast CT scan showed a large well defined unilocular, hypodense lesion measuring 9.7x8 $\mathrm{cm}$ with CT values of $+11 \mathrm{HU}$ to $+15 \mathrm{HU}$ was noted within the body and tail of pancreas. No evidence of debris, septations or mural nodule was noted. Pancreatic head and proximal body of pancreas appeared normal. Pancreatic duct appeared normal. Peri-pancreatic fat planes appeared normal. No evidence of calcification or peri-pancreatic lymphadenopathy was noted.

\section{On contrast enhanced CT:}

Parenchymal Phase: Pancreatic head and proximal part of pancreas showed normal enhancement. No evidence of enhancement of the lesion was noted. Peripheral pancreatic tissue was noted anteromedially to the lesion. Evidence of mild indentation of the splenic vein was noted. All major vessels appeared normal with normal contrast opacification. Liver, spleen, bowel and bilateral kidneys showed normal contrast enhancement.

Portal Phase: No evidence of enhancement of the lesion was noted.

Patient could not be followed up as she was referred to higher centers. 
DISCUSSION: True pancreatic cysts are rare in the general population with prevalence of $0.2 \%$ to $1.2 \%$. These low percentages may be underestimated because imaging and autopsy studies have recorded a substantially higher prevalence, about $20 \%$ to $24.3 \%$ respectively. ${ }^{3}$

Simple pancreatic cysts, also termed "true cysts, " are lined by a single layer of cuboidal epithelium and do not communicate with the pancreatic duct. They have been reported to occur in polycystic disease, fibrocystic disease or Von Hippel - Lindau disease indicating their probable congenital nature. ${ }^{4}$

CONCLUSION: Simple pancreatic cysts are typically an incidental finding in adults who have no history of pancreatic disease. The imaging characteristics of simple pancreatic cysts on CT is similar to those of benign cysts. ${ }^{5}$

This study highlights the significance of ultrasound and CT in diagnosis of pancreatic lesion. CT provides additional anatomical information, internal details of cyst and its relation to surrounding structures.

\section{REFERENCES:}

1. Demos TC, Posniak HV, Harmath C, Olson MC, Aranha G. Cystic Lesions of the Pancreas. American Journal of Roentgenology. 2002; 179: 1375-1388.

2. De Jong K, Bruno MJ, Fockens P. Epidemiology, Diagnosis, and Management of Cystic Lesions of the Pancreas. Gastroenterology Research and Practice, vol. 2012, Article ID 147465, 8 pages, 2012. doi:10.1155/2012/147465.

3. Sand J., Nordback I. The Differentiation between Pancreatic Neoplastic Cysts and Pancreatic Pseudocyst. Scandinavian Journal of Surgery 94: 161-164, 2005.

4. Marc Engelbrecht, Jennifer Bradshaw and Robin Smithuis. Pancreatic- cystic lesions. Diagnosis and management. Radiology assistant; Publication date November 3, 2012.

5. Rumack Cm, Wilson Sr, Charboneau Jw, Levine D. Diagnostic Ultrasound. 4th Ed. Elsevier; 2011:249.

6. Heindryckx E, Van Steenbergen W, Van Hoe L, Vanbeckevoort D, Ectors N, Baert AL. Solitary true cyst of the pancreas. Eur. Radiol. 8, 1627-1629 (1998).

7. Diane Bergin, Lisa M. Ho, Paul S. Jowell, Theodore N. Pappas and Erik K. Paulson. Simple Pancreatic Cysts- CT and Endosonographic Appearances. AJR Am I Roentgenol. 2002 Apr; 178(4):837-40.

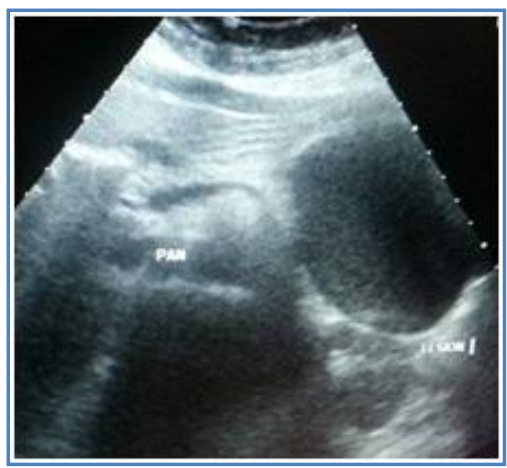

Fig.1: Ultrasound - Well defined anechoic lesion arising from tail of pancreas. 


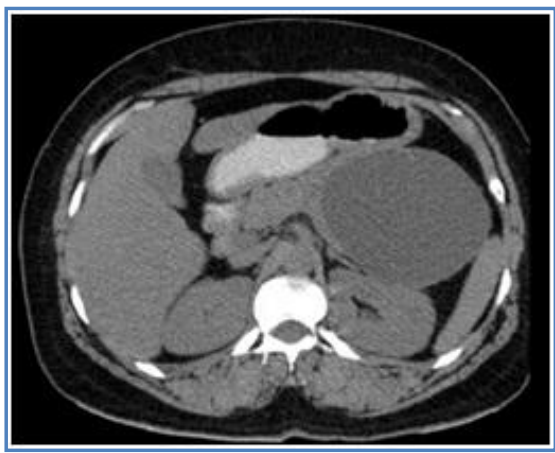

Fig. 2: Non-enhanced CT - Well-defined unilocular hypodense lesion within the body and tail of pancreas.

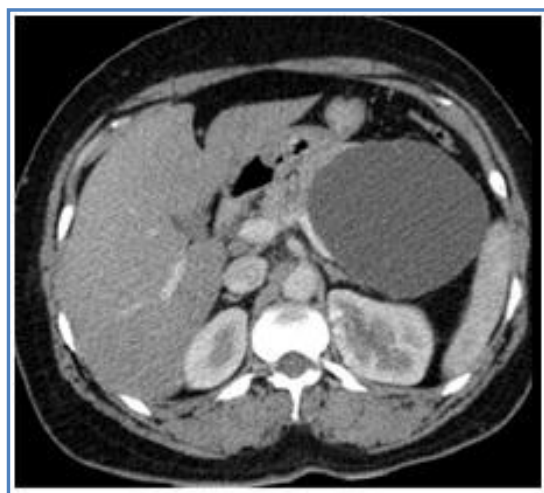

Fig. 3: Contrast enhanced CT - No evidence of enhancement of the lesion

\section{AUTHORS:}

1. Shivanand Melkundi

2. Neha Anand

\section{PARTICULARS OF CONTRIBUTORS:}

1. Associate Professor, Department of Radiodiagnosis, Mahadevappa Rampure Medical College, Gulbarga.

2. Post-Graduate, Department of Radiodiagnosis, Mahadevappa Rampure Medical College, Gulbarga.

\section{NAME ADDRESS EMAIL ID OF THE} CORRESPONDING AUTHOR:

Dr. Shivanand Melkundi, Associate Professor, Department of Radiodiagnosis, M.R. Medical College, Gulbarga. Email - drshivanandmelkundi@gmail.com

Date of Submission: 19/12/2013.

Date of Peer Review: 20/12/2013.

Date of Acceptance: 08/01/2014.

Date of Publishing: 16/01/2014. 